\title{
Aprender a Aprender, EduCAÇÃo SuPERIor e DesenVOlVimento Moral
}

\author{
Danilo Rothberg ${ }^{1}$ \\ Universidade do Sagrado Coração - Bauru, SP
}

A constituição da atitude de aprender a aprender merece atenção na medida em que é influenciada pelo estágio de desenvolvimento moral do estudante. Este artigo retoma características do processo de amadurecimento moral da criança ao adulto, detalhadas por Habermas (1989), relacionando-as à formação de conceitos tal como foi investigada por Vigotski (2000). O objetivo é indicar caminhos para a afirmação de uma postura adequada que facilite a aprendizagem no âmbito universitário e estimule a construção de um relacionamento ideal em sala de aula, em que os papéis do professor e do aluno estejam delineados com clareza.

Descritores: Ensino superior. Desenvolvimento moral. Aprendizagem.

\section{Aprender a aprender, educação superior e desenvolvimento moral}

S problemas implicados na adoção do lema "aprender a aprender" já foram descritos na crítica atenta de Duarte (2000), que o associa à tendência de restringir a educação à formação de pessoas para a adaptação às exigências do sistema econômico da atualidade. No entanto, a despeito desse contexto específico no qual a validade do lema é de fato bastante discutível, a constituição da atitude de aprender a aprender merece atenção na medida em que é influenciada pelo estágio de desenvolvimento moral do estudante.

1 Docente da Universidade do Sagrado Coração - Bauru, São Paulo e Doutor em Sociologia pela Universidade Estadual Paulista. Endereço para correspondência: Rua Pio Bigela Curiel, 1-8, Bauru, SP. CEP 17018-160. Endereço eletrônico: danroth@uol.com.br 


\section{Danilo Rothberg}

Este artigo retoma características do processo de amadurecimento moral da criança ao adulto, detalhadas por Habermas (1989), relacionando-as à formação de conceitos tal como foi investigada por Vigotski (2000). O objetivo é indicar caminhos para a afirmação de uma postura adequada que facilite a aprendizagem no âmbito universitário e estimule a construção de um relacionamento ideal em sala de aula, em que os papéis do professor e do aluno estejam delineados com clareza.

\section{Aprender a aprender e educação superior}

Duarte (2000) assinala que muitos especialistas da área de educação vêem, de maneira fragmentada, o lema "aprender a aprender" como símbolo de posições pedagógicas inovadoras e progressistas, supostamente "sintonizadas com o que seriam as necessidades dos indivíduos e da sociedade" (p. 1). O autor critica o slogan, que, segundo ele, "preconiza que à escola não caberia a tarefa de transmitir o saber objetivo, mas sim a de preparar os indivíduos para aprenderem aquilo que deles for exigido pelo processo de adaptação às alienadas e alienantes relações sociais que presidem o capitalismo contemporâneo" (p. 9).

Desta forma, o lema é acusado de representar o esvaziamento do trabalho educativo, a depreciação do papel de transmissão do saber e a descaracterização do papel do professor, já que a prioridade da educação assim entendida torna-se a mera preparação do aluno para a adaptação às novas exigências do modo de produção. Esta concepção elege como contexto preponderante o fato de que as tecnologias do sistema produtivo transformam-se rapidamente na atualidade e requerem sujeitos sempre dispostos a adquirir novas habilidades, correspondentes a diferentes processos industriais e comerciais. Daí a necessidade de formar pessoas versáteis, capazes de aprender novas tarefas tão rapidamente quanto mudam as características dos recursos tecnológicos e das interfaces com os quais elas devem lidar diariamente.

Neste quadro, o trabalho educativo estaria confinado a produzir unicamente sujeitos afinados ao imperativo social da reprodução de uma força de trabalho predisposta a enfrentar os desafios do universo econômico atual, deixando de lado outros propósitos importantes como a emancipação social, cultural e política. 
É dentro deste cenário específico que Duarte confronta o lema “aprender a aprender". O autor afirma a exigência de preservar o papel da escola na socialização do saber objetivo historicamente produzido, ampliando os "horizontes culturais" dos alunos e repelindo a tentativa de restringir a educação apenas à "satisfação das necessidades imediatas e pragmáticas impostas pelo cotidiano alienado".

Duarte aponta a existência de quatro posicionamentos valorativos sob o lema em questão, contestando sua validade. Estas quatro noções fundamentam a concepção construtivista da educação, conforme a influência piagetiana caracterizada pelo autor (Duarte, 2000, p. 34).

Segundo a primeira delas, são preferíveis as aprendizagens que o indivíduo realiza por si mesmo, sem a mediação de pessoas que transmitam seus conhecimentos ou experiências. "Aprender sozinho seria algo que contribuiria para o aumento da autonomia do indivíduo", diz Duarte. Da mesma forma, aprender algo como resultado de um processo de transmissão seria um obstáculo ao desenvolvimento autônomo do educando. $\mathrm{O}$ autor de fato considera desejável o estímulo à "iniciativa de buscar por si mesmo novos conhecimentos, a autonomia intelectual, a liberdade de pensamento e de expressão", mas não acredita que a mera transmissão de conhecimentos pelo professor possa cercear o desenvolvimento da autonomia.

O segundo posicionamento valorativo é a idéia de que o mais importante na educação é o aluno adquirir métodos de descoberta e construção de conhecimentos, ao invés de aprender aquilo que foi elaborado por outros. Além disso, o processo educativo não deveria, de acordo com esta idéia, transmitir valores morais ao aluno, mas somente o necessário para que esse indivíduo afirme-se com autonomia. "Uma educação democrática seria uma educação relativista", detalha. O aluno deveria apenas ser levado ao conhecimento de diversas opções político-ideológicas, ficando livre para escolher entre elas. Neste contexto, não seria correto oferecer uma educação alinhada ao ideário de esquerda ou direita. Caberia ao estudante julgar a validade de cada um dos posicionamentos; o professor não deve interferir.

Embora esta concepção pareça ser neutra, um olhar mais atento revela que há um importante fundamento subjacente a ela: a doutrina liberal do homem e da sociedade, o que por si só já traz consequiências ainda a serem anali- 


\section{Danilo Rothberg}

sadas com mais profundidade, aponta Duarte. E, além disso, o conceito é discutível porque as próprias referências dadas pelo professor são importantes na formação dos estudantes. "Como a criança pode aprender a julgar as distintas concepções e a adotar seu próprio ponto de vista se os adultos que a educam omitirem suas opções e seus julgamentos?", questiona o autor. Além disso, a neutralidade absoluta é inatingível. Se as religiões, por exemplo, fossem tratadas pelo professor segundo um ponto de vista supostamente neutro, que as apresentasse apenas como "fenômenos históricos e sociais", não haveria já nesta abordagem um posicionamento que toma as religiões como fenômenos produzidos pela humanidade? Ora, quando a educação assume uma perspectiva relativista e elege como valores apenas noções vagas como "liberdade, justiça, cooperação e fraternidade", o vazio dos conceitos apenas facilitaria a manipulação das consciências.

O terceiro posicionamento valorativo contido no lema "aprender a aprender" é, conforme Duarte, o princípio segundo o qual "a atividade do aluno, para ser verdadeiramente educativa, deve ser impulsionada e dirigida pelos interesses e necessidades" do próprio educando. Aqui, há dois problemas: de um lado, a educação pode resvalar no mero emprego dos meios de comunicação para incorporar conteúdos de uma cultura de massa pobre e degradante ao cotidiano escolar; de outro, as aulas passariam a centrar-se no desenvolvimento de capacidades exigidas pelo mundo de trabalho, desvalorizando a formação política e cultural.

Este último aspecto é a essência do quarto e último posicionamento valorativo, o de que "a educação deve preparar os indivíduos para acompanharem a sociedade em acelerado processo de mudança". Aqui, está a ênfase na exigência de formar recursos humanos aptos à competição por postos de trabalho na luta contra o desemprego. A formação da "capacidade adaptativa" dos indivíduos afirma a importância do desenvolvimento da criatividade, mas esta aptidão é considerada apenas naquilo que se relaciona à "capacidade de encontrar novas formas de ação que permitam melhor adaptação aos ditames do processo de produção e reprodução do capital". Ou seja, esta concepção merece ser criticada porque renuncia à obrigação de construir sujeitos emancipados do ponto de vista social, cultural e político, além de reduzir o processo educativo à formação de trabalhadores ajustados às exigências atuais de um sistema econômico em veloz transformação. 
Descritos até aqui os problemas implícitos na adoção irrefletida do lema "aprender a aprender", pretende-se apontar um sentido diferenciado que ele pode assumir na educação superior. Na verdade, há uma mínima relação entre os posicionamentos valorativos apresentados acima e o significado que queremos evidenciar. Esta revisão da análise de Duarte teve o propósito de despir a expressão "aprender a aprender" de outros significados que ela pode representar, procurando clarear o terreno para a afirmação de um sentido diverso.

Deve ser considerado, inclusive, que há níveis de ensino que valorizam explicitamente a conversão dos propósitos educativos à adaptação das pessoas ao sistema econômico, como a educação de nível técnico profissionalizante. No entanto, ao contrário deste nível, que tem, inclusive segundo a Lei de Diretrizes e Bases da Educação Nacional (Lei n. 9.394/96), uma sintonia inegável com o aprender a aprender as capacidades adaptativas para o trabalho, a educação superior assume de acordo com a mesma legislação um caráter mais abrangente.

Ou seja, enquanto, segundo o artigo 39 da LDB, "a educação profissional, integrada às diferentes formas de educação, ao trabalho, à ciência e à tecnologia, conduz ao permanente desenvolvimento de aptidões para a vida produtiva", o nível superior tem por finalidade, segundo o artigo 43 da mesma lei, "estimular a criação cultural e o desenvolvimento do espírito científico e do pensamento reflexivo" (inciso I), "incentivar o trabalho de pesquisa e investigação científica, visando o desenvolvimento da ciência e da tecnologia e da criação e difusão da cultura, e, desse modo, desenvolver o entendimento do homem e do meio em que vive" (inciso III), "promover a divulgação de conhecimentos culturais, científicos e técnicos que constituem patrimônio da humanidade e comunicar o saber através do ensino, de publicações ou de outras formas de comunicação" (inciso IV) e "suscitar o desejo permanente de aperfeiçoamento cultural e profissional e possibilitar a correspondente concretização, integrando os conhecimentos que vão sendo adquiridos numa estrutura intelectual sistematizadora do conhecimento de cada geração" (inciso V).

Se está claro que a educação superior não pode ser reduzida à mera formação de capacidades adaptativas às exigências do mundo do trabalho, cabe analisar de que maneira esse nível de ensino pode de fato lograr seus intentos superiores. Ora, não é novidade que seus docentes convivem diariamente com alunos que parecem interessados apenas em adquirir as competências requeri- 


\section{Danilo Rothberg}

das para o exercício imeditato de funções em dado contexto de trabalho. São estudantes que encaram qualquer exercício de reflexão sobre a prática profissional como algo monótono e irrelevante.

Naturalmente, poderiam ser levantadas aqui diversas críticas ao próprio desempenho docente e à organização curricular, muitas vezes responsabilizados pelo desestímulo à ampliação dos horizontes culturais da educação superior. No entanto, na medida em que não é o objetivo do presente artigo apresentar ou discutir essas críticas, cabe examinar somente as deficiências discentes possivelmente responsáveis pela dramática redução da qualidade de ensino nas faculdades e universidades brasileiras.

Assim, o enfoque aqui se dá sobre a disposição dos universitários em aceitar, eles próprios, as finalidades da educação que lhes chega nesse nível, colocando-se, no cotidiano das aulas, de forma compatível com os elevados propósitos do ensino superior.

A tarefa de elevar a qualidade da aula universitária esbarra no desejo do aluno de encontrar ali um conhecimento meramente instrumental, que lhe permita o rápido ingresso no mercado de trabalho, ainda que em funções de remuneração e integridade discutíveis. Os docentes debatem-se então com um cenário de difícil resolução: se devem "promover a divulgação de conhecimentos culturais, científicos e técnicos que constituem patrimônio da humanidade e comunicar o saber através do ensino", conforme o trecho da LDB citado acima, no dia-a-dia conseguem tão-somente disseminar um número pequeno de técnicas profissionais, adquiridas pelos alunos sem reflexão sobre as razões de sua existência ou das possibilidades de uso em função de necessidades éticas e sociais subjacentes ao universo profissional.

O que parece estar em jogo nesse contexto é o imperativo de o universitário ser levado a perceber a amplitude dos desafios que precisa enfrentar. Ele deve ser alçado a uma posição de abertura às exigências da formação de nível superior e precisa ser preparado para atender às expectativas apresentadas pela sociedade. Não se deve permitir que o universitário abrigue-se sob um manto de indiferença e apresente um desempenho regular, desenvolvendo-se de forma parcial e fragmentada. A formação superior deve estimular a aquisição do saber e proporcionar o desenvolvimento da capacidade de refletir sobre a adequação desse saber às necessidades sociais. Desta forma, um meio de os 
docentes oferecerem uma solução a esse dilema, com o qual lidam diariamente, é levar seus alunos a aprenderem a aprender. Isto é, os universitários devem compreender por que devem aprender aquilo que se faz necessário ao exercício profissional social e eticamente responsável. O docente deve estar consciente de que precisa criar meios para estimular a disposição do aluno em acolher o conhecimento socialmente relevante; é preciso parar de aceitar que o aprendizado em nível universitário fique restrito à transmissão do conhecimento meramente instrumental.

Neste contexto, aprender a aprender adquire um significado específico. Agora, o lema quer dizer que o educando deve aprender a dispor-se de forma compatível ao que dele se espera na universidade. Ele deve aprender a aprender os conteúdos desse nível de ensino, considerando a verdadeira dimensão da sua responsabilidade individual, que exige que aqueles conhecimentos sejam empregados de forma ética e socialmente adequada. $\mathrm{O}$ aluno não pode limitar-se àquilo que lhe parece ter utilidade imediata; ao contrário, deve ser levado, pelo professor, a aprender a construir a abertura imprescindível à percepção de como determinadas técnicas profissionais devem ser aplicadas em sintonia com o interesse social.

O leitor poderia apontar que, neste percurso aqui desenvolvido, carece de fundamentação a noção de ética profissional exercida em acordo com o interesse social. Assim, cabe questionar: haveria um sentido específico para a moralidade da atuação individual dentro do contexto social? Quais princípios éticos o indíviduo precisa respeitar caso tenha em mente a preservação do contrato social historicamente consolidado? E, caso esse significado particular já tenha sido explicado científica e filosoficamente, teria o universitário em determinada idade já desenvolvido a capacidade de compreendê-lo e agir em concordância com ele? Ou seja, considerando que o aluno na fase universitária possui um equipamento sócio-cognitivo próprio de quem apenas deixou a adolescência há cinco anos, em média, teria esse sujeito a capacidade de aprender a aprender, neste último sentido apresentado aqui?

Na busca de uma resposta satisfatória a estas questões e, em consonância com os objetivos propostos por este artigo, é oferecida a seguir uma revisão do conceito de agir comunicativo, segundo Habermas (1989). Esta noção proporciona a compreensão de como se desenvolve, do ponto de vista da Psicologia, a 


\section{Danilo Rothberg}

habilidade da ação orientada ao entendimento mútuo, a qual, acredita-se aqui, é pré-requisito para o desenvolvimento do aprender a aprender a disposição necessária às exigências superiores da formação moral no ensino universitário.

\section{Consciência moral}

Um dos objetivos da ciência psicológica desde suas origens é compreender o processo de desenvolvimento moral da criança ao adulto, passando pelas peculiaridades dos avanços próprios da adolescência. Deste modo, foram formuladas teorias que buscam captar as características mais relevantes do percurso, integrando-as em um modelo único. Habermas (1989) seleciona uma delas, segundo a qual o desenvolvimento da capacidade de julgar moral efetua-se da infância até a idade adulta através da passagem por seis estágios distintos.

O autor considera essa teoria como um dos pilares de sua ética do discurso, que ele oferece na tentativa de relacionar a consciência moral como elemento fundador do agir comunicativo, isto é, da inserção do falante no universo de relações sociais com objetivos específicos.

O primeiro estágio é aquele dentro do qual a obediência literal às regras e à autoridade se faz unicamente como maneira de evitar a punição. Nesta etapa, as razões para fazer o que é direito "são o desejo de evitar o castigo e o poder superior das autoridades" (Habermas, 1989, p. 152). O egocentrismo domina a criança. As ações próprias são julgadas principalmente em relação aos seus efeitos físicos. "A perspectiva da autoridade é confundida com a própria” (p. 159).

No segundo estágio de desenvolvimento moral, o que é direito está restrito ao atendimento das próprias necessidades, ainda que considerando o

efeito coercitivo dos interesses das outras pessoas. É possível separar os próprios interesses daqueles interesses atribuídos às outras pessoas, identificando possíveis conflitos entre eles. Mas a troca ainda é a maneira de remediar os atritos: a boa vontade diante do interesse alheio justifica-se somente mediante uma compensação ofertada em contrapartida.

Estas duas fases estão em um nível pré-convencional, no qual as regras de comportamento não são percebidas como um corpo organizado e dependem de estímulos ou sanções objetivas para serem seguidas. 
O terceiro estágio inaugura o nível convencional, em que as convenções que regem o comportamento passam a ser visualizadas e aceitas enquanto tais. Aqui, vale a "regra de ouro": o sujeito passa a ter necessidade de sentir-se bom perante seus próprios olhos e aos olhos dos outros e pode imaginar-se sob a perspectiva dos outros olhando para ele. "Uma pessoa neste estádio está cônscia de sentimentos, acordos e expectativas compartidos, que adquirem primazia sobre interesses individuais".

O dever de contribuir para a sociedade, o grupo ou a instituição caracteriza o quarto estágio do desenvolvimento moral. Agora, o direito é "fazer o seu dever na sociedade, apoiar a ordem social e manter o bem-estar do grupo" (Habermas, 1989, p. 153). As leis devem ser apoiadas e, as obrigações, cumpridas em nome do bem da coletividade. $\mathrm{O}$ sujeito compreende os papéis tais como a sociedade os regula.

O quinto estágio desencadeia o nível pós-convencional, no qual as decisões morais "são geradas a partir de direitos, valores ou princípios com que concordam (ou podem concordar) todos os indivíduos compondo ou criando uma sociedade destinada a ter práticas leais e benéficas". O sujeito deve estar consciente de que o direito é agir conforme regras cuja validade e imparcialidade provêm do contrato social e orientam-se pela opinião da maioria. Leis e deveres são baseadas no "cálculo racional de utilidade geral", segundo o qual o maior bem subordina-se ao imperativo do maior número de pessoas incluídas no pacto. A imparcialidade ganha objetividade, justificada em nome dos mecanismos formais do acordo socialmente concebido.

O sexto e último estágio do desenvolvimento moral "presume a orientação por princípios éticos universais" de validade reconhecida racionalmente pelo sujeito, que escolhe agir de acordo com eles. "A perspectiva é a de qualquer indivíduo racional que reconhece a natureza da moralidade ou a premissa moral básica do respeito por outras pessoas como fins, não meios".

A passagem de um estágio para o outro pressupõe um aprendizado, e significa que "a pessoa em crescimento transforma e diferencia de tal maneira as estruturas cognitivas já disponíveis em cada caso que ela consegue resolver melhor do que anteriormente a mesma espécie de problemas, a saber, a solução consensual de conflitos de ação moralmente relevantes". 


\section{Danilo Rothberg}

Em cada estágio superior, o sujeito torna-se capaz de perceber o quão errados estavam os julgamentos apoiados sobre a estrutura anterior. Neste contexto, o desenvolvimento da capacidade de julgar moralmente é o resultado de uma "reorganização criativa do inventário cognitivo pré-existente".

Segundo Habermas, a adolescência é caracterizada pelo súbito abandono do estágio convencional, no qual as regras estão ancoradas em julgamentos de validade assentida de forma automática e irrefletida, para uma fase na qual a própria substância da realidade precisa ser reconstruída, em um difícil processo de doação de novos significados às próprias ações e às dos outros. "De um só golpe, o mundo social das relações interpessoais legitimamente reguladas - mundo esse ingenuamente habitualizado e reconhecido sem problemas - se vê desenraizado e despido de sua validade nativa". No momento em que o adolescente percebe como vazias de sentido autêntico as regras que alimentavam suas vivências, cada norma precisa ser refeita a partir dos "destroços das tradições desvalorizadas e devassadas como meras convenções carentes de justificação". Agora, desvanecem-se as ilusões, e as regras em vigor são consideradas em duas possibilidades: de um lado, alinham-se aquelas que são reconhecidas como tais pela sociedade; de outro lado, são postas aquelas dignas de reconhecimento pelo próprio sujeito.

O momento crítico é uma "catástrofe" com algo de "anti-natural", sublinha o autor, significando um "rompimento com a ingenuidade das pretensões de validade erguidas diretamente e de cujo reconhecimento intersubjetivo depende a prática comunicativa do quotidiano".

Assim, a argumentação, de caráter ético, é posta em ação para reconstruir o sentido das ações comuns e substituir o agir guiado por regras pelo discurso orientado ao exame dessas regras. A verdade dos enunciados e a correção das normas passam a ser discutidos de forma argumentativa. A pretensão de validez de cada norma é avaliada na nova estrutura de interação social. "Na argumentação, o oponente e o proponente disputam uma competição com argumentos para convencer um ao outro, isto é, para chegar a um consenso", detalha Habermas (1989, p. 194). A uma "estrutura dialética de papéis", correspondem formas discursivas para a "busca cooperativa da verdade".

Esta ética do discurso remete, de acordo com o autor, a uma teoria do agir comunicativo orientado para gerar o entendimento mútuo entre os partici- 
pantes de um diálogo. $\mathrm{Na}$ argumentação, valem reciprocidades e relações de reconhecimento em torno das quais giram as idéias morais. A universalidade dos termos do entendimento está ancorada na atitude reflexiva dos falantes, que examinam continuamente as próprias pretensões e as dos outros em um contexto de normas sociais compartilhadas. Neste quadro, os pressupostos universais do discurso estão distribuídos de maneira equânime. O falante não os escolhe a cada nova prática comunicativa; eles são exigidos automaticamente pelo agir refletido. A interação é, afinal, orientada por juízos morais, realizando-se de forma lingüística no cotidiano, e as pretensões de validez de cada enunciado são assumidas dentro do quadro do mundo social consentido, o que exige, por sua vez, que a compreensão da sociedade seja descentralizada do próprio ego.

O agir orientado ao entendimento mútuo é uma fase de superação do agir unicamente orientado à obtenção do sucesso pessoal, destaca Habermas (1989). Isto é, quando uma interação depende dos cálculos egocêntricos de ganhos e perdas que cada um dos sujeitos faz intimamente, a estratégia de ação baseia-se em ataques, ameaças e seduções, implícitos ou explícitos. O grau de cooperação advém, nesta circunstância, somente da possibilidade de haver interesse especial em submeter-se a tais regras de conversação - em casos nos quais exista, por exemplo, recompensa vantajosa o suficiente para um participante curvar-se, ainda que provisória ou falsamente, à alegada lógica do outro.

Já o agir orientado para o entendimento mútuo exige a coordenação dos objetivos de atores distintos. "O acordo não pode ser imposto à outra parte, não pode ser extorquido ao adversário por meio de manipulações”, diz o autor (Habermas, 1989, p. 164). O acordo deve partir de convicções comuns. Um plano de ação deve erigir-se sobre interpretações comuns dos diversos aspectos envolvidos naquela ação, constituindo-se a partir do consenso.

Ao mesmo tempo, o falante deve estar apto a assumir as perspectivas do destinatário, em um processo reflexivo e circular que também se entrelaça às perspectivas de mundo; o falante é "produto das tradições nas quais se encontra, dos grupos solidários aos quais pertence e dos processos de socialização nos quais se cria", segundo Habermas (1989, p. 164). O ambiente social dá o contexto e os meios para o entendimento mútuo. "O mundo da vida comum em cada caso oferece uma provisão de obviedades culturais donde os participantes da comunicação tiram seus esforços de interpretação e os modelos de exegese consentidos". 


\section{Danilo Rothberg}

Este "saber proposicional compartido intersubjetivamente" não é, no entanto, o bastante para estabelecer o agir orientado ao entendimento mútuo. Desta forma, os atos de fala não servem apenas à representação de fatos do mundo da vida, mas também à auto-representação de papéis e expectativas (cada participante deve afirmar a si próprio, suas perspectivas, sua experiência e sua disposição para o diálogo) e, sobretudo, à produção (ou renovação) de relações interpessoais capazes de alimentar a confiança mútua.

As competências exigidas do falante são complexas e abrangem três esferas, correspondentes às funções dos atos de fala. Em primeiro lugar, ele precisa dominar o repertório lingüístico suficiente para objetivar certas concepções culturais e categorias de realidade às quais se refere e acredita serem consensuais; em segundo lugar, ele deve saber expressar suas vivências e conceitos pertinentes, à luz do mesmo saber social já posto em comum; por fim, é necessário colocar-se, diante de relações interpessoais legitimadas, de forma compatível com as regras de comportamento compartilhadas.

Estes três universos são intercambiáveis e alimentam-se mutuamente: cada elemento da realidade é continuamente entrelaçado às perspectivas pessoais, que devem, por sua vez, ser apresentadas conforme as normas de relacionamento, elas próprias sujeitas a um valor cultural estabelecido anteriormente.

A complexidade das relações entre as diferentes perspectivas em questão qualifica justamente o resultado de um processo em que a visão de mundo torna-se completamente descentrada. As perspectivas do falante, do destinatário e do mundo da vida passam a ser diferenciadas e seguem normas reconhecidamente cabíveis a cada um dos três pontos de vista. Aqui, a totalidade da interação social ganha substância e sua composição pode ser discernida. $\mathrm{O}$ equipamento sócio-cognitivo é aperfeiçoado para dar conta da normatividade dessas três esferas e a comunicação torna-se agir comunicativo organizado com a finalidade de gerar entendimento mútuo.

Nesta nova estrutura de organização do diálogo, "os envolvidos podem não apenas assumir reciprocamente suas perspectivas de ação, mas também trocar as perspectivas de participante pela perspectiva de observador e transformá-las uma na outra", conforme Habermas (1989, p. 180, grifos nossos). 
Vale destacar que, dentro das normas culturais consentidas, está a autoridade impessoal que cada ser socializado internaliza. A possibilidade de um falante enganar o outro está, em tese, excluída a partir do momento no qual as categorias de realidade socialmente aceitas são verdadeiramente partilhadas pelos sujeitos. O papel que o destinatário espera do falante, no contexto das normas estabelecidas, não admite o logro. Este somente torna-se uma alternativa atraente ao falante quando as regras que constituem o pano de fundo do agir orientado ao entendimento mútuo não foram suficientemente introjetadas. Assim, o conceito de arbítrio suprapessoal, que reprime a atitude de induzir alguém a engano como estratégia competitiva em uma interação, constitui o mundo social em sua "totalidade de relações interpessoais legitimamente reguladas". E a validade destas relações existe na medida que elas exigem funções recíprocas: os integrantes de um grupo social desempenham seus papéis sociais na consciência de que possuem o direito de esperar uns dos outros determinadas ações e estão obrigados a preencher as expectativas de comportamento dos demais.

$\mathrm{Na}$ passagem do universo convencional para o pós-convencional, a nova circunstância de interação social exige a formulação de novos juízos, já que tudo se torna hipoteticamente válido ou inválido. Neste momento, "o adulto escapa à ingenuidade da prática quotidiana" e se desprende do mundo tradicional das normas existentes, observa Habermas (1989, p. 195). Agora, "à luz das pretensões de validez hipotéticas, o mundo dos estados de coisas existentes é teorizado, o mundo das relações ordenadas de maneira legítima é moralizado". O que era simplesmente tido como válido é examinado e precisa tornar-se digno de ter sua validade reconhecida. $\mathrm{O}$ sujeito abandona a condição de dependência das normas preexistentes e reconstrói suas ações com base em julgamentos que faz com autonomia. Agir de forma responsável adquire outro sentido neste contexto. "A responsabilidade torna-se um caso especial de imputabilidade; esta significa a orientação do agir em função de um acordo representado de maneira universal e motivado racionalmente - age moralmente quem age com discernimento" (p. 195).

Agir para o entendimento mútuo supõe orientar-se por pretensões de validez reflexivamente avaliadas pelos sujeitos em cada um dos papéis, de forma recíproca; daí sua moralidade, que somente pode surgir no estágio pós- 


\section{Danilo Rothberg}

convencional. "O agir moral está sob a pretensão de que a solução de conflitos de ação só se apóia em juízos fundamentais - trata-se de um agir guiado por discernimentos morais".

Fica claro, a partir daqui, que o agir comunicativo orientado ao entendimento mútuo é uma atitude ideal, possível somente em um estágio avançado de desenvolvimento moral. No entanto, existem problemas em supor que todas as pessoas possam facilmente chegar até esta etapa. Habermas (1989, p. 210) reconhece que a teoria do desenvolvimento moral apresenta questões que merecem ser estudadas. Entre elas, duas importam para a análise aqui empreendida: a) quais são as diferentes saídas que uma pessoa em crescimento pode seguir quando estanca no momento em que não mais reconhece as certezas convencionais e precisa reconstruir o significado das normas sociais? Ora, os críticos da teoria, aponta o autor, alegam que, se o esquema dos seis estágios for aplicado rigorosamente, "mais da metade da população dos Estados Unidos ficaria aquém do plano pós-convencional da consciência moral”; b) quais são as distorções entre juízos morais e ações quando o agir orientado ao sucesso pessoal e o agir orientado ao entendimento mútuo não são separados no processo de desenvolvimento moral?

Habermas não chega a aprofundar-se nestas questões, posto que seu objetivo é buscar as bases da teoria apenas para fundamentar seu conceito de agir comunicativo. No entanto, estas duas indagações levantam suspeitas que merecem um tratamento específico dentro do percurso aqui desenvolvido.

A questão "a" levou à introdução, à teoria, do estágio intermediário 4 1⁄2 para caracterizar justamente os sujeitos que, emboram tenham abandonado a fase convencional, não evoluíram para o nível pós-convencional.

De fato, o estágio 4 1⁄2 parece descrever adequadamente a situação do adolescente tardio que, não completando o processo de desenvolvimento moral, carece de fundamentos para exercer papéis socialmente regulados e agir orientado ao entendimento mútuo.

"No estágio 4 1⁄2, a escolha é pessoal e subjetiva. Está baseada em emoções, a consciência é vista como arbitrária e relativa, como o são idéias como 'dever' e 'moralmente correto"”, detalha Habermas (1989, p. 220). "O equipamento sócio-cognitivo do estádio convencional da interação foi reorganizado, 
então, apenas até o ponto em que, tendo aprendido, é verdade, argumentações teóricas, o adolescente se detém diante da entrada na argumentação moral".

Quando as convenções perdem a "força ingênua da validez social" e tornam-se, assim, "reflexivamente desvalorizadas", há dois caminhos possíveis. O sujeito pode encontrar fundamentos racionais para reconstruir a normatividade do tecido social, condição primeira para a passagem ao modo de pensar pós-convencional. Ou pode simplesmente desprender-se da fase convencional sem passar à pós-convencional. "Nesse caso, [o adolescente] compreende o desmoronamento do mundo das convenções como o devassamento da falsidade de uma pretensão cognitiva, à qual estavam associadas até aí as normas e proposições deontológicas convencionais", aponta Habermas.

E, nesse momento, os conceitos morais subitamente desvalorizados vão precisar de explicação. O sujeito deve resolver a dissonância entre as intuições morais, que continuam determinando seu conhecimento e suas ações de forma não-refletida, e a provável percepção do caráter ilusório daquela consciência moral convencional. Esta, embora desvalorizada, preenche precariamente a função de guia no cotidiano do adolescente. "No lugar de uma consciência ética pós-convencionalmente renovada aparece uma explicação meta-ética das ilusões morais", diz o autor. Ou seja, entram em ação explicações fundamentadas em conceitos que situam-se além da ética, em um contexto amoral. Não são mais referências morais legitimadas socialmente que vão orientar o agir comunicativo, mas algo estranho aos papéis exigidos pelo entendimento mútuo.

Uma das possibilidades é, então, que o adolescente oriente seu agir comunicativo pela busca do sucesso pessoal. No entanto, ele vai precisar erguer barreiras psíquicas para defender-se das reações de reprovação social que este comportamento pode desencadear. $\mathrm{O}$ aspecto estratégico do agir exclusivamente segundo interesses pessoais permanece inconsciente, assim como inconscientes conservam-se os desejos que buscam satisfação por essa via. Desta forma, este procedimento particular pode ser revestido pela aparência do agir orientado ao entendimento mútuo. "É assim que o sujeito pode se enganar a si mesmo quanto ao fato de que ele infringe objetivamente as pressuposições compartilhadas do agir orientado para o entendimento mútuo", explica Habermas. Neste quadro, "o efeito de um auto-engano do ato de defesa pode ser interpretado no sentido de um distúrbio intrapsíquico da comunicação". 
Ora, para que a transição para o nível pós-convencional se complete, são exigidas certas capacidades intelectuais. Para avaliar de forma coerente a correção do próprio ponto de vista, diante das perspectivas das outras pessoas com interesses distintos em situações comuns, é necessário dispor da faculdade de construir conceitos complexos o suficiente para abranger as semelhanças e as diferenças entre múltiplos posicionamentos pessoais.

Ou seja, para superar as estratégias da busca do sucesso pessoal, não basta ter noções superficiais sobre os papéis exigidos pelo agir orientado ao entendimento mútuo. Para que o sujeito possa completar o descentramento de sua visão de mundo e tornar-se capaz de agir refletidamente em consideração às perspectivas sociais e dos outros, é imprescindível formar conceitos abrangentes. Desta forma, a formação de conceitos, tal como foi investigada por Vigotski (2000), pode assumir um papel chave no percurso de desenvolvimento moral da criança ao adulto.

A seguir, é oferecido um resumo da conceituação de Vigostki sobre a construção do pensamento, adicionando mais uma etapa ao percurso desenvolvido aqui.

\section{Formação de conceitos e desenvolvimento moral}

A operação intelectual que estabelece relações lógicas entre determinados elementos, agrupando-os sob um conceito representado por um signo verbal, só pode surgir após os doze anos de idade, conforme estudos citados por Vigotski (2000, p. 154). Após essa idade, o pensamento torna-se desenvolvido o suficiente para operar os processos pelos quais a compreensão do mundo pode se dar da maneira abstrata característica do adulto.

A questão central do processo de formação de conceitos é, segundo Vigotski (2000, p. 169), "o emprego funcional do signo ou da palavra como meio através do qual o adolescente subordina ao seu poder as suas próprias operações psicológicas, (...) domina o fluxo dos próprios processos psicológicos e lhes orienta a atividade no sentido de resolver os problemas que tem pela frente". 


\section{Aprender a Aprender, Educação Superior e Desenvolvimento Moral}

Assim, a solução de problemas é o fim ao qual se dirigem operações mentais que são a substância da formação de conceitos. Como consequiência desta afirmação, pode-se dizer que

onde o meio não cria os problemas correspondentes, não apresenta novas exigências, não motiva nem estimula com novos objetivos o desenvolvimento do intelecto, o pensamento do adolescente não desenvolve todas as potencialidades que efetivamente contém, não atinge as formas superiores ou chega a elas com um extremo atraso. (Vigotski, 2000, p. 169)

Para proporcionar a compreensão das diferenças entre o pensamento por conceitos e as formas de pensamento anteriores, é necessário descrever as fases percorridas pela criança. A investigação conduzida por Vigotski aponta que a evolução que culmina no desenvolvimento dos conceitos constitui-se de três estágios distintos.

No primeiro deles, ocorre a formação de uma "pluralidade não informada e não ordenada, a discriminação de um amontoado de objetos vários", que é "unificado sem fundamento interno suficiente, sem semelhança interna suficiente e sem relação entre as partes que o constituem" (Vigotski, 2000, p. 175). Nesse ponto, a criança tende a substituir a "carência de nexos objetivos por uma superabundância de nexos subjetivos e a confundir a relação entre as impressões e o pensamento com a relação entre os objetos". Os vínculos existem somente no universo das impressões da criança, e não externa e objetivamente.

No segundo estágio, as generalizações são feitas não mais a partir de impressões subjetivas, mas sim com base em atributos concretos que realmente existem nos objetos. Aqui, a criança já superou até certo ponto seu egocentrismo. O pensamento se dá por complexos e é "coerente e objetivo", indica o autor. Esta etapa apresenta uma forma de pensamento mais elaborada do que a anterior, mas ainda distinta daquela que será desenvolvida no terceiro e último estágio, o do pensamento por conceitos. "O mais importante para construir um complexo é o fato de ele ter em sua base não um vínculo abstrato e lógico [como ocorre com o conceito] mas um vínculo concreto e fatual entre elementos particulares que integram a sua composição", distingue Vigostki. As diferenças entre conceito e complexo são marcantes: "No conceito, os objetos estão generalizados por um traço, no complexo, pelos fundamentos fatuais mais diversos. Por isso, no conceito se refletem um vínculo essencial e unifor- 


\section{Danilo Rothberg}

me e uma relação entre os objetos; no complexo, um vínculo concreto, fatual e fortuito".

A exemplo do conceito, o complexo também é uma generalização de objetos heterogêneos. Mas, no complexo, os objetos estão ligados por vínculos casuais diversos, freqüentemente sem nada em comum entre si, enquanto o conceito se baseia em vínculos logicamente idênticos.

Nos complexos, os vínculos podem ser de cinco tipos. Em primeiro lugar, na evolução da criança, estão os de tipo associativo, que ocorrem quando os objetos são agrupados sob um mesmo complexo em função de uma semelhança física com um objeto modelo. Em segundo lugar, os vínculos podem existir na forma de coleções, quando os diversos objetos são heterogêneos, mas complementam-se. Em terceiro, está o complexo por cadeia, no qual os elementos integram-se por determinados elos que compõem um série; cada um deles transmite seu significado para o resto do conjunto, de forma desconexa com o sentido dos primeiros elos. "Cada elo está unido, por um lado, ao anterior e, por outro, ao seguinte, cabendo ressaltar que a característica mais importante desse tipo de complexo consiste em que pode ser muito diferente o caráter do vínculo ou o modo de combinação do mesmo elo com o anterior e o seguinte", detalha Vigotski (2000, p. 186).

Em quarto lugar, no processo de desenvolvimento do pensamento por complexos, está o pensamento por complexo difuso. Neste nível, o atributo comum aos elementos constituintes do complexo é flexível e transforma-se de maneira fluida, já que a criança passa a reconstruir constantemente os critérios para compor os agrupamentos que dão sentido ao universo sensível. Assim, as generalizações são inesperadas, muitas vezes inteligíveis ao adulto, e próprias do momento a partir do qual a criança arrisca-se a pensar além de seu pequeno mundo direto e ousar a compreender questões que estão além de sua experiência imediata.

O último estágio do desenvolvimento do pensamento por complexos é o pseudoconceito, no qual a generalização, embora possa gerar um resultado coincidente com o produto da formação de conceitos, ocorre de fato por meio de complexos. A formação de pseudoconceitos e a construção de conceitos verdadeiros são operações intelectuais completamente distintas, enfatiza Vigostski (2000). A diferença está na relação entre os elementos estabelecida pelo pensamento em cada caso. No pseudoconceito, a conexão entre seus integrantes 
ainda é estabelecida de forma mecânica; o indivíduo não possui a capacidade, característica da formação de conceitos, de avaliar a natureza das leis que unem o conjunto. Somente o conceito possui ligações lógicas entre seus componentes que podem ser objeto de exame e reflexão por parte do sujeito.

Apesar de esta distinção, a semelhança entre o pseudoconceito e o conceito deve ser vista com atenção, já que o primeiro "coincide com o conceito e de fato abrange o mesmo círculo de objetos concretos que abrange o conceito" (Vigostski, 2000, p. 193). Isto é, do ponto de vista funcional, ambos desempenham papel parecido: organizam a realidade e orientam o comportamento.

Na criação de um pseudoconceito, a relação entre os elementos vêm pronta do exterior por meio do contato com pessoas que já conhecem a lógica das leis do conceito equivalente. Desta forma, a formação de um pseudoconceito dispensa a faculdade de perceber a lógica das conexões subjacentes a um grupo de elementos; a operação intelectual de discernir a natureza das ligações em questão não é requerida. O significado do agrupamento de rudimentos é simplesmente "emprestado" das outras pessoas, de maneira a prescindir da devida compreensão de seu estatuto interno.

No entanto, no cotidiano, o sujeito que apenas domina o pseudoconceito comunica-se normalmente com aquele já capaz de formar conceitos, já que ambas as formas de pensar, possuindo o mesmo caráter instrumental, servem para que os participantes de um diálogo refiram-se às mesmas realidades. Mas deve ficar claro que, a despeito de a diferença não ser perceptível na prática comunicativa diária, o sujeito que forma pseudoconceitos simplesmente não exerce a faculdade mental de perceber a coerência entre os elementos do conceito equivalente.

Neste sentido, Vigotski (2000, p. 217) destaca que, embora a superação do pseudoconceito pela operação de formação de conceitos verdadeiros seja algo marcante no percurso do desenvolvimento psicológico da criança ao adulto, muitas vezes o próprio adulto emprega pseudoconceitos inadvertidamente. Não porque não disponha da faculdade de construir conceitos, mas devido à falta de conhecimento suficiente para perceber toda a dimensão das leis que regulam um dado agrupamento. Desta forma, com pseudoconceitos "também se verifica com grande frequiência o transcorrer do pensamento no nosso dia-a-dia", sublinha o autor. 


\section{Danilo Rothberg}

Na verdade, "os conceitos não são conceitos propriamente ditos na forma como se encontram no nosso discurso cotidiano", quando são, afinal, "noções gerais sobre as coisas", diferenciando-se dos "verdadeiros conceitos no sentido dialético desta palavra". O conceito em sentido lato "pressupõe não só a combinação e a generalização de determinados elementos concretos da experiência", mas, inclusive, "a discriminação, a abstração e o isolamento de determinados elementos e, ainda, a habilidade de examinar esses elementos discriminados e abstraídos fora do vínculo concreto e fatual em que são dados na experiência".

Assim, embora somente a adolescência seja o momento a partir do qual o pensamento por conceitos se torne possível, ela não deve ser vista como um período de conclusão do desenvolvimento, mas de "crise e amadurecimento do pensamento", diz o autor (Vigostski, 2000, p. 229). Mesmo os conceitos do adulto, "uma vez que sua aplicação se restringe ao campo da experiência puramente cotidiana, freqüentemente não se colocam acima do nível dos pseudoconceitos".

A diferença torna-se inteiramente visível quando se exige do sujeito que enuncie a lógica interna de um conceito. Ele pode, é verdade, empregá-lo corretamente em uma situação concreta; pode organizar a realidade e comunicar-se com os outros com certa eficiência, "mas tão logo entra em pauta a definição verbal desse conceito o seu pensamento esbarra em dificuldades excepcionais".

Ou seja, aplicar um conceito em uma situação concreta é algo relativamente fácil, se comparado ao processo de transferência de conceitos, que exige a aplicação de experiências anteriores a objetos heterogêneos, "quando os atributos discriminados mas sintetizados nos conceitos se encontram em outro ambiente de atributos concretos bem diferentes". No entanto, observa Vigotski, é ainda mais difícil a definição verbal de um conceito, porque essa tarefa não pode apoiar-se sobre experiências concretas, devendo fundamentarse sobre o plano abstrato da linguagem pura, que exige a referenciação a novos aspectos, ainda não vivenciados.

Em resumo: se consideramos que os verdadeiros juízos só podem ser construídos unicamente por meio de operações de abstração, percebemos que, muitas vezes, o desenvolvimento da capacidade de formação de conceitos 
simplesmente não se completa; nesse sentido, assume-se a possibilidade de que adultos continuem organizando sua imagem do mundo com pseudoconceitos, noções generalizantes não avaliadas de forma refletida, de maneira que a coerência interna entre seus elementos tende a permanecer ignorada pelo sujeito. Embora o indivíduo possa agir com a naturalidade de quem domina o conceito, já que, do ponto de vista instrumental, como visto acima, o conceito e sua forma antecessora sejam semelhantes, na verdade as relações lógicas subjacentes a um dado juízo conservam-se desconhecidas; o sujeito não consegue alargá-las para, integrando outros elementos a uma dada perspectiva, ampliar a compreensão da realidade.

E, se o verdadeiro sentido do conceito não for compreendido, "esquemas verbais mortos e vazios" vão fazer as vezes de sua definição verbal, diz Vigotski (2000, 247). Ou seja, a chave para o entendimento de um conceito não pode ser imposta de fora no processo de aprendizagem escolar, sob pena de o educando reter apenas verbalizações superficiais que, embora muitas vezes transmitam a impressão de que ele compreendeu as leis do conceito, ocultam o fato de que, na verdade, as leis das generalizações necessárias àquela compreensão permanecem inteligíveis - apesar de serem encobertas por um manto de formulações pontuais que permitem a comunicação entre educador e educando.

Neste contexto, o objetivo da aprendizagem deve ser proporcionar a compreensão das leis que regem cada generalização, de forma que os conceitos sejam percebidos como sistemas, caracterizados por uma organização lógica e asbtrata.

Ora, com isso é possível perceber que o docente no ensino superior tem seus objetivos frustrados quando constata que o aluno apenas adquiriu uma noção precária dos conceitos-sistemas tratados nas aulas. Muitas vezes, os nexos lógicos entre seus elementos internos não são percebidos, e o aluno, quando solicitado, apresenta uma formulação rasteira e vazia como definição verbal do conceito. O professor, se atento, pode até perceber que isso ocorre, mas se vê com freqüência impossibilitado ou incapaz de reverter um processo que, aparentemente, foi concluído. Afinal, o aluno parece dominar o conceito, já que é capaz de oferecer uma descrição qualquer; no entanto, é inegável que a substância interna do conceito, sua lógica interna como sistema, não foi devidamente apreendida. 


\section{Danilo Rothberg}

Uma prova clara desse fato vem à tona quando o docente solicita que o aluno exemplifique o conceito, ou seja, que aponte outros de seus elementos integrantes. Naturalmente, dominar apenas uma verbalização vazia sobre o conteúdo de um conceito não significa que se tenha a capacidade de inventariar outros elementos caracterizados pelos mesmos atributos. O aluno, então, estanca; não é capaz de compreender a natureza do conceito a ponto de incorporar logicamente outros elementos a ele.

Também é possível perceber uma aprendizagem que não houve, quando o próprio docente apresenta outro elemento de um mesmo conceito já visto em classe antes. Muitas vezes, poucos alunos são capazes de perceber as relações entre antigos e novos elementos, de forma que o professor, mais uma vez, sente-se frustrado ao notar que uma relação que ele supôs tão óbvia à classe - afinal, presente em um conceito já estudado - permanece opaca aos alunos.

A partir daqui, já é possível aproximar-se das conclusões que se pretendem oferecer neste artigo, esclarecendo por último a natureza diversa que pode ser assumida pela noção de "aprender a aprender".

\section{Conclusões}

Se compreender a função social de uma tarefa ou comportamento profissional exige enquadrá-la dentro de complexas descrições de perfis de desempenho ocupacional, o que significa familiarizar-se com as leis que regulam generalizações muito abrangentes, então aqui tornam-se visíveis as razões pelas quais os universitários retêm apenas aspectos limitados da profissão que estão aprendendo. Isto é, acostumados a guiar-se por noções gerais no lugar de conceitos verdadeiros, compostos de forma refletida, eles assumem como normal a atitude de apreender o sentido imediato de determinada rotina profissional. Os alunos não se preocupam com os reflexos sociais de dada conduta profissional, não somente porque sejam "alienados" ou "individualistas", como freqüentemente são considerados por docentes exasperados com uma situação de aprendizagem impossível, mas porque seu equipamento sóciocognitivo simplesmente não está habituado a fazer as operações intelectuais normalmente requeridas ao exercício profissional socialmente responsável. 
Embora muitos possam acusar esses alunos de insensibilidade social (o que, certamente, pode ser correto em muitos casos), o problema é, na verdade, da ordem do desenvolvimento psicológico, que, por sua vez, leva a um problema da ordem do desenvolvimento moral. Ou seja, conforme Habermas, a capacidade de julgar moralmente exige a avaliação reflexiva das perspectivas socialmente legitimadas em relação à afirmação das próprias intenções. Claro está que a capacidade de julgar moralmente exige a capacidade de formar os conceitos correspondentes. Se age moralmente quem age com discernimento, segundo o autor, podemos também afirmar que age moralmente somente quem forma os conceitos equivalentes. Neste contexto, a capacidade de construir conceitos verdadeiros, no sentido descrito por Vigotski, é pré-requisito para a capacidade de julgar e agir moralmente. Como consequiência, pensar por complexos ou por noções gerais não-refletidas, nas quais as relações entre os elementos são compreendidas apenas mecanicamente, não é suficiente para pensar e agir moralmente.

Assim, o universitário não compreende a dimensão da responsabilidade social de sua profissão porque não está habituado às operações intelectuais requeridas para tanto. Se ele vê como importantes somente os saberes necessários à execução imediata de dada tarefa profissional, é porque seu pensamento está guiando-se por noções fragmentadas, semelhantes àquelas que qualquer adulto têm diante de si quando não dispõe de conhecimentos aprofundados o suficiente para explicar a natureza das leis que regem um conceito.

Esta conclusão pode ser vista como inusual enquanto resposta para explicar os problemas de aprendizagem na educação de nível superior. Tradicionalmente, universitários insensíveis às demandas sociais e preocupados somente em aprender aquilo que lhes parece ter utilidade imediata têm sido vistos como produto de uma sociedade de consumo em que o individualismo e a alienação são posturas hegemônicas. Também se apontam deficiências no currículo, no desempenho docente, na oferta de infra-estrutura tecnológica, bibliotecas etc.

No entanto, a perspectiva resumida aqui não poderia nem pretende negar a plena validade dessas respostas usualmente dadas aos problemas em questão. Trata-se, tão-somente, de indicar um caminho para aqueles que, a despeito das circunstâncias objetivas que de fato afetam o ensino - interesses 


\section{Danilo Rothberg}

imediatistas e pragmáticos do corpo discente, falta de recursos pedagógicos etc -, sentem-se compelidos a mudar o quadro.

Afinal, quando o individualismo dos alunos e a escassez de recursos são tidos como principais obstáculos à consecução dos objetivos superiores do ensino universitário, a consequiência é, muitas vezes, o imobilismo; os docentes tendem simplesmente a renunciar à sua missão e resignam-se aos parcos resultados que conseguem colher.

No entanto, se o obstáculo passa a ser considerado como uma certa forma de pensamento caro aos alunos, dependente de um dado estágio de desenvolvimento psicológico e moral, então o problema adquire uma nova dimensão, que pode ser devidamente enfrentada em sala de aula.

As leis que regem o conceito enquanto sistema precisam ser objeto de extenso exame e debate em sala de aula. E somente situações objetivas da prática profissional de uma área, recriadas e analisadas em aula, são exemplos que podem mostrar as consequiências nocivas de tarefas desempenhadas sem consideração às éticas social e de cada profissão. Os métodos de avaliação não devem privilegiar a formulação vazia de conceitos, mas sim requerer o desenvolvimento de habilidades nas quais seja verificada a dimensão ética da tarefa profissional avaliada.

Por fim, o universitário deve ser levado a aprender a aprender. Ele precisa compreender seu papel em uma sociedade com tantas desigualdades e deve saber que essa sociedade exige dele um desempenho ético. Emprestando as palavras de Habermas, vale dizer que o aluno deve abandonar as estratégias voltadas à busca do sucesso pessoal - busca que só pode resultar no aprendizado do sentido imediato das funções profissionais ensinadas, sem consideração à sua dimensão moral. $\mathrm{O}$ aluno deve, sim, agir voltado à busca do entendimento mútuo, o que exige ter sempre em mente as perspectivas socialmente legitimadas e a ótica dos outros indivíduos presentes em um dado contexto social, respeitando-as e vivendo de acordo com o mais elevado estágio de desenvolvimento psicológico e moral.

Isto requer atenção especial do docente. Convém lembrar que, muitas vezes, os alunos que estão nas instituições de ensino superior particulares têm um história peculiar de relacionamento com seus professores desde o ensino 
fundamental. E essa relação foi caracterizada por conflitos freqüentes. Não é possível generalizar, mas muitos desses estudantes tendem a ver o professor como alguém com interesses opostos aos seus: é aquele sujeito que exige, critica e reprova, mostrando-se eternamente insatisfeito com o desempenho dos alunos.

Daí ser natural, para esses educandos, agir conforme estratégias orientadas à obtenção do sucesso pessoal. A busca dos alunos por meras notas mínimas de aprovação, apesar de deixar muitos docentes desolados, acaba prevalecendo sobre qualquer desejo de aprender de fato e torna-se padrão até na universidade. E, para se obter apenas uma nota média de aprovação, a maior parte das avaliações exige uma mera formulação vazia, que substitui a apreensão de conceitos.

Completa-se o círculo: o aluno domina apenas noções gerais simplesmente porque está acostumado a guiar-se por elas, afinal mais fáceis de construir; o professor é percebido como um obstáculo ao desempenho dos estudantes, já que é visto como um sujeito essencialmente crítico e, portanto, desmotivador; por fim, a avaliação é feita de tal forma que permite a obtenção de notas de aprovação somente com o domínio de noções gerais. E numerosas classes passam ao semestre seguinte sem conhecer conceitos elementares a respeito da dimensão ética e da responsabilidade social da formação profissional que estão recebendo.

Por isso, é imprescindível o professor universitário mover-se dentro de um terreno específico. Ele deve ter em mente que os alunos oferecem uma resistência consolidada ao longo de muitos anos de experiência escolar repleta de conflitos e, na medida em que consideram improvável estabelecer uma relação de cooperação com o professor, preferem agir segundo uma estratégia voltada à busca do sucesso pessoal. Além disso, se o professor propositalmente oferecer avaliações que aprovem alunos conhecedores de noções gerais apenas, ele estará estimulando justamente o desenvolvimento dessa estratégia.

Ao contrário, é preciso construir em sala de aula um diálogo marcado por papéis claros de cooperação, que permitam, à luz das exigências aclaradas por Habermas, o estabelecimento de relações de confiança fortes o suficiente para fundamentar o agir orientado à busca do entendimento mútuo. Já que este processo exige exatamente a transparência dos papéis dos envolvidos 


\title{
Danilo Rothberg
}

no diálogo, os alunos tenderão a ver o professor como parceiro na formação de conceitos e, assim, darão o primeiro passo para, com uma capacidade de aprendizado ampliada, conhecer a natureza de sua responsabilidade social como universitários.

Em resumo, defendem-se aqui dois traços de uma noção específica do "aprender a aprender" válida para a docência no ensino superior. Em primeiro lugar, o professor deve distinguir, entre os alunos, a formação de noções gerais e verbalizações vazias, de um lado, e a formação de conceitos abrangentes, de outro lado, buscando didáticas que privilegiem o segundo caminho de aprendizado - seja examinando experiências profissionais à luz das implicações éticas, analisando e debatendo as leis das generalizações sob os conceitos-sistemas estudados ou adotando outros métodos adequados a cada caso. O resultado disto, para o educando, é a percepção do que significa de fato aprender. Em segundo lugar, é necessário estimular os estudantes a adotar perspectivas de ação orientadas ao entendimento mútuo em sala de aula. $\mathrm{O}$ resultado disto é a construção de relações de cooperação específicas, com o objetivo de proporcionar a abertura suficiente ao aprendizado de toda a dimensão ética do conhecimento que importa a determinado campo profissional. Neste sentido, espera-se formar sujeitos compatíveis com as expectativas morais da sociedade democrática liberal da atualidade.

Rothberg, D. (2006). Learning to learn, college degree and moral development. Psicologia USP, 17(2), 85-111.

\begin{abstract}
The constitution of the atitude of learning to learn requires attention since it is influenced by the phase of moral development of the student. This article reviews characteristics of the process of moral maturation from the child to the adult, detailed by Habermas (1989), relating them to the formation of concepts as it was researched by Vigostki (2000). The purpose is to indicate ways for the affirmation of an adequate posture that facilitates learning in the academic ambit and stimulates the construction of an ideal relationship in the classroom, in which the roles of the teacher and of the pupil be clearly described.
\end{abstract}

Index terms: Higher education. Moral development. Learning. 
Rothberg, D. (2006). Apprendre à apprendre, diplome universitaire et développement moral. Psicologia USP, 17(2), 85-111.

Résumé: La constituition de l'attitude d'apprendre à appendre exige d'attention, vu qu'elle est influencé par la phase de développement moral de l'étudiant. Cet article révise les caractéristique du processus du maturation moral de l'enfant jusqu' à l'adulte, détaillé par Habermas (1989), associé à la formation du concepts, comme recherché par Vigotski (2000). L'objetif c'est indiquer des routes pour l'affirmation d'une posture appropprié qui facilite l'apprentissage dans l'ambiance académique et stimule la construction d'une relation idéale dans la salle de cours, dans laquelle les rôles du professeur et de l'élève soient décrit clairement.

Mots-clés: Diplome universitaire. Développement moral. Apprentissage.

\section{Referências}

Duarte, N. (2000). Vigotski e o "aprender a aprender": crítica às apropriações neoliberais e pós-modernas da teoria vigotskiana. Campinas, SP: Autores Associados.

Habermas, J. (1989). Consciência moral e agir comunicativo. Rio de Janeiro: Tempo Brasileiro.

Lei n. 9.394, de 20 de dezembro de 1996. Estabelece as diretrizes e bases da educação nacional. Diário Oficial da União, seção 1.

Vigostki, L. S. (2000). A construção do pensamento e da linguagem. São Paulo: Martins Fontes.

Recebido em: 25.09.2005

Aceito em: 21.11.2005 